\title{
The Coronal Place; Why is It Special?
}

\author{
Azhar Alkazwini \\ The Public Authority For Applied Education And Training (Paaet), Kuwait
}

Corresponding Author: Azhar Alkazwini, E-mail: aasalkb@hotmail.com

\section{ARTICLE INFO \\ Article history \\ Received: May 11, 2017 \\ Accepted: July 14, 2017 \\ Published: December 01, 2017 \\ Volume: 6 Issue: 7 \\ Special Issue on Language \& Literature Advance access: September 2017}

Conflicts of interest: Non

Funding: None

\begin{abstract}
To prove the existence of arguments about the exact place that can bear the term 'coronal', it would be enough to check the explanatory dictionary's entry. There are different arguments regarding the exact place of coronal. In this paper, some of the linguistic evidence regarding the coronal place shall be mentioned. Then, I shall discuss the classes of coronal that lend support to the fact that coronal place is believed to be special, and that is by discussing the different typologies of coronal consonants and giving their description.
\end{abstract}

Key words: English Language, The Coronal Place, Coronal Consonants, Organs of Articulation, Classes of Coronals, Phonetics, Linguistics

\section{INTRODUCTION}

A number of phoneticians consider the Coronal Place to be special. In this paper, I summarize some of the linguistic evidence regarding the coronal place. Then, I discuss the classes of coronal that lend support to the fact that coronal place is believed to be special, and that is by discussing the different typologies of coronal consonants and by giving their description in detail.

\section{DISPUTES ABOUT THE CORONAL PLACE}

\section{Dictionary Entries}

To prove the existence of arguments about the exact place that can bear the term 'coronal', it would be enough to check the explanatory dictionary's entry. One of the most detailed explanations would give such lexico-semantic variants:

- Frontal; articulated with the tip of the tongue, especially in a retroflex position

- (in distinctive feature analysis) articulated with the blade of the tongue raised; dental, alveolar or palate-alveolar;

- $\quad$ of or pertaining to the tip of the tongue (WED 1996 , p. 453).

As it can be seen, two basic parts of the tongue that are mentioned in this aspect are: the tip of the tongue and the tongue blade.

\section{Scholarly Evidence}

According to Hall (1997), "Coronal sounds are articulated with the front part of the tongue and therefore include not only segments produced in the denti-alveolar region. ...but also sounds articulated just behind the alveolar ridge" (p.04). According to C. Paradis and J. F. Prunet (1992), "Coronal consonants are phonologically special" (p.363). When P. Ladefoged (2007) discusses places of articulation and terminology, he states that phonetically speaking, the articulation of 'apical' happens with the tip of the tongue, and the 'coronal' refers to the articulation that happens by the tongue blade. 'Coronal' also refers to both of these places of articulation unless the language that is being discussed has more characteristics. When considering the place of articulation of coronal, there are some points that are vague, especially with regard to the relationship between the tip of the tongue, the tongue blade and the front of the tongue. These phrases may mean different things to different phoneticians.

According to J. Mielke and E. Hume (2006, p.724), in 'The Encyclopedia of Language and Linguistics' front or central region of the tongue is mentioned as one of the distinctive features of the coronals' articulation.

According to Kohler (2007, p. 41-53), this is a problem that concerns all consonants in the majority of world languages as there is no certainty about the distribution of place and manner of articulation. The same problem is discussed 
by Keating (1991, p. 29-31). She mentions the blade (including the tip) as the coronals' typical organ of articulation. Keating then discusses in length the different approaches regarding how long the tip may be. There are two traditions. In British phonetics, the blade includes the tip and $10-15 \mathrm{~mm}$ of the tongue. In American studies, (because of the differences in the pronunciation of the retroflex) the tip is equal to the blade in British studies, and the 'American' blade is further to the back. Thus the tip and the blade together would approximately measure $20-25 \mathrm{~mm}$ long. P. Keating believes that the blade alone is about $15-20 \mathrm{~mm}$. P. Ladefoged (2007) gives the length of a centimeter making the coronal place rather short.

Keating (1991) also gives a descriptive analysis of this part naming it "the most mobile", "the part not attached to the floor of the mouth, roughly corresponding to the part below the alveolar ridge" (p.31). She also attributes the special status and length of the coronal place to the function of the tongue (Idem) which is a strong decision considering the numerous classes of coronals.

According to Ladefoged (2007), from a linguistic and phonetic perspective, one of the most beneficial definitions for the 'blade of the tongue' is based on its association with the roof of the mouth. The 'blade' is the part of the tongue that is located under the middle part of the alveolar ridge when the tongue is resting.

In many works, the term 'coronal' is not even introduced. When Crystal (2003, p. 236) describes the organs of speech, he names the parts of the tongue as: the tip, the blade 'which is the tapering part opposite the alveolar ridge', the front part 'which is opposite the hard palate', the center of the tongue 'where the hard and soft palate meet', and the back of the tongue 'opposite the soft palate'. The use of the term 'coronal' is avoided by both Davenport and Hannahs (2005) 'Introducing Phonetics and Phonology', and Balland Rahilly (2013) 'Phonetics: the Science of Speech'.

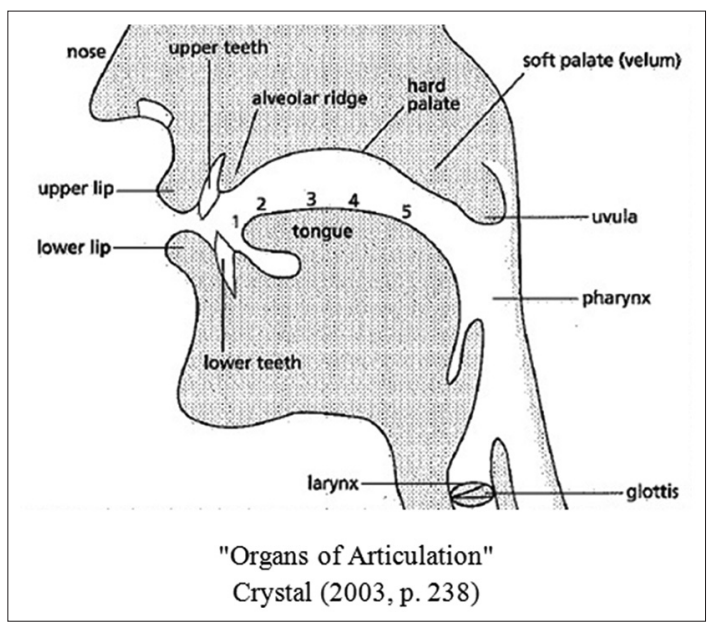

Judging by this diagram in Crystal (2003, p. 238(, which illustrates the anatomic location, the length of the coronal place can vary. It may measure from $10 \mathrm{~mm}$ (includes only the tip, corresponding to Ladefoged) to $15-20 \mathrm{~mm}$ if the blade is included (British tradition). It can also measure 25-30 mm (American studies, Keating) or even 35-40 mm
(ELL, P. Keating) if both the front and central parts are included. Images in Ball and Rahilly (2013) are also proof of the differences in the length of the coronal place. According to P. Ladefoged (2007), one cannot be specific about these matters because the tongue is a 'continuous body' that does not have anatomical features, in addition to that is the fact that everyone's mouth is different in shape.

According to Arbisi-Kelm and Beckman (2009, p. 109136), differences can also depend on the individual anatomy of speech organs. It can also depend on the gender and age variations. Examples of the gender and age differences in addition to the prosodic dependence of coronals can be found in Livijn and Engstrand (2001, p. 108-111). According to J. Blevins (2007, p. 144-154), the 'assimilation' and 'dissimilation' process along with 'mishearing' results in the different age and gender groups can also be taken as evidence for the existence of various typologies.

\section{CLASSES OF CORONALS}

\section{The Problem of Division}

The problem of classes is a result of the problem of non-stability as far as the place of articulation is concerned. According to P. Keating (1991, p. 29), both the place and manner of articulation of coronal being convenient are an explanation for the reason as to why there are so many of the them in all languages of the world. At the same time, this type of consonants gives more contrasts than any other type.

According to Keating (1991, p. 29-31), relying on J. Maddieson's survey, there are five primary places of articulation that are given the term 'coronal': dental, alveolar, palatoalveolar, retrofle and palatal. Another two positions are also mentioned: linguolabial and interdental. The interdental is due to the status of $/ \theta /$ and $/ \partial /$ phonemes. At the same time, there are five other primary places of articulation that exist that account for the formation of all the other consonants. Therefore, coronals form a very large group.

Recasens (2013, p. 02) classifies coronal consonants into: anterior, palatoalveolar, alveolopalatal and palatal. Schwartz, Boe and Abry (2007, p. 109) describe four positions for coronal articulation groups: dental, alveodental, alveolar, and postalveolar. They also mention the convenience of the articulation and the variety of combinations. "In fact, systems with the three places of articulation (labial, coronal, velar) constitute 33 percent of the languages, while systems with the four places of articulation (labial, coronal, palatal, velar) constitute 7.5 percent of the systems" (Schwartz et al., 2007, p.104-124). Engstrand, Frid and Lindblom (2007, p. 179-180) describe dental, prealveolar, postalveolar, retrofle, and strongly retrofle coronal types. For this, these characteristics are used:

1) The position parameter (the location where the main tongue hump is).

2) Displacement parameter (how far the tongue is displaced from its neutral structure).

3) The mandible and the tongue contour.

These typologies of consonants: apico- (tongue tip), lamino- (blade), dorso- (tongue body), and radico- (tongue 
root) are given by Ball and Rahilly (2013, p. 53). According to the place of articulation there are subtypes.

As I previously mentioned that those scholars avoid the term 'coronal', yet the analysis of this diagram leads to the inclusion of all dentoalveolar types, postalveolar and palatal from the domal type into coronals. According to the diagram, it would be a problem to include retroflex sounds into coronals although they do discuss the term 'retroflex'. "[Retroflex] is a term that describes the tongue's shape rather than its place of articulation. It may well be more precise therefore to use the term 'sublaminal (pre)palatal' suggested by Catford (1988)" (Ball and Rahilly, 2013, p.56).

Davenport and Hannahs (2005, p. 18-37) also avoid the term 'coronal'. They describe these classes of consonants: bilabial, alveolar, velar, palatoalveolar, labiodental, dental, glottal, labiovelar, palatal, alveolar-lateral or rhotics or liquids. As it can be seen, this description is based on place, manner and organ of articulation all at the same time. What is interesting is how they describe the allophones ' $r$ ' that may belong to different types including coronals. They analyze five allophones as

1) "The alveolar 'trill' is when the tongue blade vibrates repeatedly against the alveolar ridge. This allophone is frequent in Scottish dialects;

2) The alveolar tap is produced with a single tap of the tongue back against the alveolar ridge. This allophone is also found in Scottish dialects;

3) The alveolar continuant $/ \mathrm{r} /$ is produced when the tongue blade is raised towards the alveolar ridge and the sides of the tongue are in contact with the molars and it forms a narrow channel down the middle of the tongue. This allophone is found in British English dialect;

4) The retroflex $/ \mathrm{r} /$, is very similar to the alveolar continuant $/ r$, but with the tongue blade curled back to the position of the post-alveolar. This is found in North American and South West English dialects;

5) The uvula roll / $\mathrm{r} /$, or fricative / $\mathrm{r}$ /are produced with the back of the tongue that vibrates against the velum or is close to it. This is found in rural Northumberland, parts of Scotland, French and High German”, (M. Davenport and J. Hannahs, 2005, p.32).

This typology crosses and intersects with a detailed analysis in Engstrand (2007, p. 175-191). A long discussion is given about the perceptual and articulatory bridge between coronal and dorsal ' $r$ ' allophones in the Swedish dialects. The fact that the Anglo-Saxon dialects were under the Scandinavian influence and the general typology about the languages of the world that English and Swedish belong to the same group of Germanic languages may be a reason for some similarities. Relying on Ladefoged and Maddieson (Their studies are based on English sound systems), they state that "the rhotics (r sounds) are known for having a particularly wide range of phonetic variation" (Engstrand, 2007, p.175). They describe some types found in Swedish dialects: 'front' (coronal) and 'back' (dorsal), fricatives, trills, taps and flaps, and vocoids. Also 'bunched'/r/s where front and back difference does not work because this type is a combination of allophones. There is much similarity with $/ \mathrm{r} /$ allophones as mentioned above between the British, Scottish and American variants. It is believed that "dorsal and coronal rhotics do not contrast phonologically in any known living language and should not be subject to strong perceptual categorization" (Engstrand, Frid and Lindblom, 2007, p.183). "These observations suggest that perception affects place of articulation in rhotics". (p.176)

The reasons for front rhotics changing into back rhotics, and evidence for the existence of a perceptual motivation is then discussed. "This suggests that changes in place of articulation for rhotics may be phonetically motivated and, thus, likely to take place from time to time in the world's languages. In particular, the polygenetic scenario regarding the origin of back rhotics in Europe would stand out as reasonable» (Engstrand, Frid and Lindblom, 2007, p.191). Front allophones may come as a result of developments that happen later. This includes labialization and reduction of gesture formation.

According to J. Mielke and E. Hume (2006, p. 724) in (ELL, Distinctive Features), the category of coronals generalizes more specific phonetic types: interdental (pronounced with the tip of the tongue between the teeth), alveolar (pronounced with the front part of the tongue raised up in direction of the alveolar ridge), and palatal (-alveolar) (pronounced with the central part of the tongue raised towards the roof of the mouth). The coronals include: $/ \mathrm{r} /, / \mathrm{l} /, \mathrm{t} /, / \mathrm{d} /, / \theta /$, $/ \mathrm{d} /, / \mathrm{n} /, / \mathrm{s} /, / \mathrm{z} /, / \mathrm{ts} /, / \mathrm{t} \mathrm{l} /, \mathrm{d} z /, / \mathrm{J} /, / 3 /$. As it can be seen, the term 'interdental' is used instead of the term 'dental', but the sounds

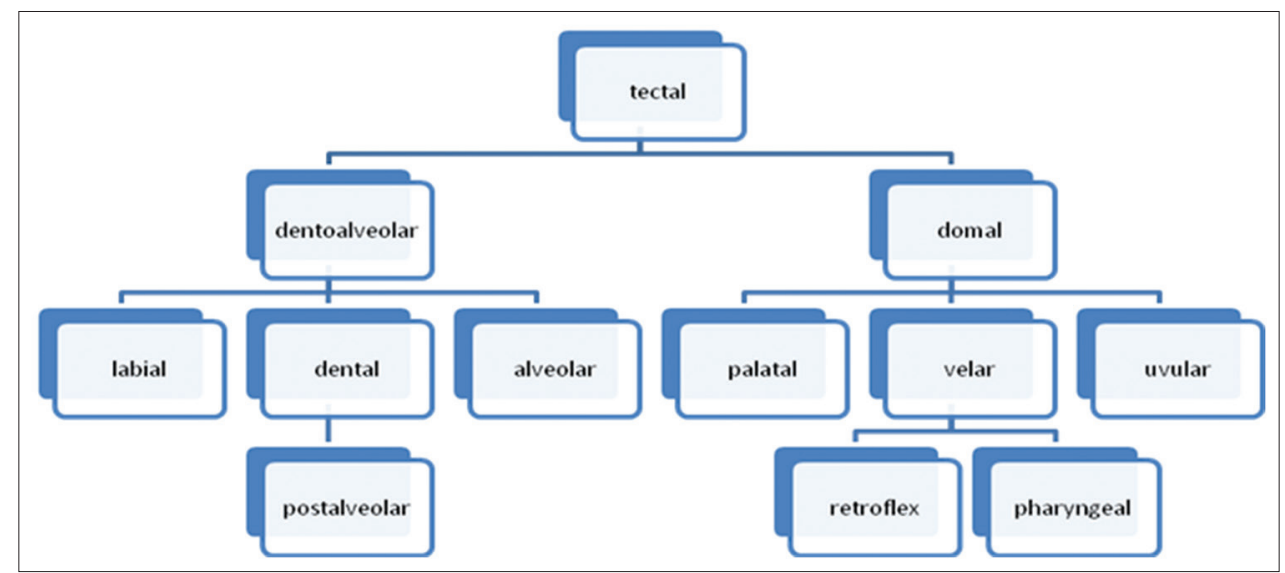

Ball and Rahilly (2013, p. 54) 
are the same. There is no term 'retroflex (rhotics or liquids), but instead the phoneme ' $r$ ' is included into the alveolar type.

$\mathrm{K}$. Kohler gives these types of coronal: dental, alveolardental, alveolar and postalveolar (Kohler 2007, p. 41-48). He also tries to define the status of coronal as being either labial or dorsal.

\section{Typology by P. Ladefoged}

One of the most detailed descriptions is given by P. Ladefoged (2007). He believes that in English there is a strong distinction between interdental (also called dental) and alveolar. The alveolar phonetically may be either apical or coronal.

In his article, the English phonemes $/ \theta /, / \mathrm{d} /, / \mathrm{s} /, / \mathrm{z} /, / \mathrm{t}, / / \mathrm{d} /, / \mathrm{n} /$ are all referred to as apical. They differ from the standard usage in phonetics. The phonemes $/ \mathrm{t} \mathrm{J} /, \mathrm{d} z /, / \mathrm{J} /, / 3 /$ are referred to as palatal in terms of the place of articulation. The phonemes $/ \theta /, /$ / are treated as a separate class of interdentals in terms of their manner of articulation. They are opposed to fricative, stop, nasal, etc. The affricates $/ \mathrm{t} / /, \mathrm{d}_{3} /$ are treated as palatal stops in opposition to the palatal fricatives $/ \mathrm{J} /, / 3 /$. Ladefoged also discusses the phonetic affricates $/ \mathrm{ts} /, / \mathrm{dz} /$, that only occur in the final position of a syllable, except for borrowings that are phonetically integrated. He also gives reasons for why $[\mathrm{t}]$ ] and $[\mathrm{ts}]$ are treated differently in the English Language.

Another interesting point is that alongside the inclusion of phonemes that are not really traditional, Ladefoged excludes palatal sounds from the class of coronals. This contrasts with Keating, Ball and Rahilly. His decision is based on the definitions of the tongue blade and on the alveolar ridge. According to Ladefoged (2007), the palatal sounds are not articulated by raising the tongue blade. They are produced by the part of the tongue that is traditionally known as the 'front' (of the body) of the tongue. The centre part of the alveolar ridge allows us to give meaning to the three parts of the vocal tract that are related to the articulation of coronal. The sounds that are produced with the use of the teeth are 'dental', the sounds that are produced from behind the teeth with the front part of the alveolar ridge are 'alveolar', and lastly the sounds produced directly behind the alveolar ridge are 'postalveolar'. These differences allow us to define the two features that the coronal node dominates; 'Apicality' and 'Anterior'. 'Apicality' is the feature that specifies the action of the active lower articulation, and 'Anterior' is the feature that specifies the upper passive articulator that is involved.

Ladefoged also repeats J. Maddieson's criticism which is that many scholars do not show any difference between apical and laminal gestures, or between dental and alveolar sounds.

\section{Recasens' Opposing View}

P. Ladefoged's view is strongly opposed in (Recasens 2013, p. 1-22). D. Recasens argues that if we exclude palatal sounds from the class of coronals then we do not take into account the following two points:
(1) A primary articulator that involves two lingual articulators that are together such as the blade and the dorsum of the tongue.

(2) A place of articulation that is being mixed up and it extends over two articulation zones that are together such as the alveolar and palatal.

Instead, the author introduces the term 'alveolopalatal consonants'. They come as a result of a simultaneous stopping or narrowing at the alveolar and palatal areas. At the same time, a primary articulator surrounds the blade and the dorsum of the tongue. "Their place of articulation may include the postalveolar zone and the prepalate, but also a larger contact area extending towards the front alveolar zone and the back palate surface. The tongue tip is bent downwards and the tongue dorsum is raised and fronted during the production of these consonants. Alveolopalatals differ from palatoalveolars (which are also labeled postalveolar) in that the latter are articulated at the postalveolar zone exclusively, may involve the tongue tip as primary articulator and exhibit less tongue dorsum doming" (Recasens, 2013, p.02).

Based on P. Keating's investigations, Recasens states that alveolopalatals used to be considered complex segments. These segments were likely to be produced with two lingual gestures. The gestures are independent (a primary coronal gesture and a secondary tongue dorsum raising and fronting gesture) and are activated almost at the same time. This made them different from both coronal and dorsal. It provides the particular status of alveolopalatals. He supports the fact that there are many cases when different allophones of the same phonemes may change their class and articulatory gestures (especially in the flow of speech). They may move from the palatal, postalveolar class into alveolopalatal and back. This depends on the inter-linguistic and extra-linguistic factors. A language may show a preference for either one or the two places of articulation. The allophone in its turn may become coronal.

\section{CONCLUSION}

In conclusion, coronals are a special class of consonants due to the fact that they can be made in so many ways. The tongue blade is a very flexible part and, as a result, it produces more different articulations than other speech organs (Keating, 1991, p. 30). Another fact is that due to the different approaches along with the various phonetic processes, the coronal place is considered to produce a variety of consonants and their positional merges.

\section{Abbreviations}

ELL: The Encyclopedia of Language and Linguistics.

OED: Oxford English Dictionary.

WED: Webster's Encyclopedic Unabridged Dictionary of the English Language.

\section{REFERENCES}

Arbisi-Kelm, T. and Beckman, M. E. (2009). Prosodic structure and consonant development across languages. Pho- 
netics and phonology: interactions and interrelations. Vigário M., Frota S., Freitas M. J. (Eds.). Amsterdam studies in the theory and history of linguistic science. Series IV, Current issues in linguistic theory. Vol.306. The Netherlands: USA: Amsterdam, Philadelphia: John Benjamins B.V. - P.109-136.

Ball, M., and Rahilly, J. (2013). Phonetics: The Science of Speech. School of Psychology and Communication, School of English; The Queen's University of Belfast. Arnold Publishers. USA: NY.

Blevins, J. (2007). Experimental Approaches to Phonology. Interpreting Misperception Beauty is in the Ear of the Beholder. Sole, M.J, Beddor, P. and Ohala M. (Eds.). Oxford: Oxford University Press. USA: New York. p.144-154.

Crystal, D. (2003). The Cambridge Encyclopedia of the English Language. Cambridge University Press. USA: New York.

Davenport, M. and Hannahs, S. J. (2005). Introducing Phonetics and Phonology. Hodder Arnold: UK.

Engstrand, O., Frid, J. and Lindblom, B. (2007). Experimental Approaches to Phonology. A Perceptual Bridge Between Coronal and Dorsal /r/. Sole, M.J, Beddor, P. and Ohala M. (Eds.). Oxford: Oxford University Press. USA: New York. p.175-191.

Hall, T. (1997). The Phonology of Coronals. Current Issues in Linguistic Theory 149. Vol. 149. John Benjamins. Amsterdam/Philadelphia.

Keating, P. (1991). Coronal places of articulation. The special status of coronals: Internal and external evidence 2. Paradis C. \& Prunet J. (Ed.). Academic Press. San Diego: CA, p.29-48.
Kohler, K. (2007). Beyond Laboratory Phonology: The Phonetics of Speech Communication. Experimental Approaches to Phonology. Solé M., Speeter Beddor P. and Ohala M. (Eds.). Oxford: Oxford University Press. USA: NY. p.41-53.

Ladefoged, P. (2007). Linguistic Phonetic Descriptions. The Handbook of Phonetic Sciences. Hardcastle W. J., Laver J. (Eds.). Blackwell Publishing, 1999. Blackwell Reference Online. 28 December 2007.

Livijn, P. and Engstrand, O. (2001). Identifying places of articulation in coronal consonants: A combined EPG and listening test. Lund University, Dept. of Linguistics. Working Papers 49, p.108-111.

Mielke, J. and Hume, E. (2006). The Encyclopedia of Language and Linguistics. Distinctive Features. Brown K. (Ed.). Elsevier: Pergamon Press.

Paradis, C. and Prunet, J. F (1992). The Special Status of Coronals: Internal and External Evidence. Phonology. McCarthy, J. and Taub, A. (Reviewers). Cambridge University Press.

Recasens, D. (2013). On the articulatory classification of (alveolo)palatal consonants. Journal of the International Phonetic Association, 43(1), p.1-22.

Schwartz, J. L., Boe, L. J. and Abry C. (2007). Linking Dispersion-Focalization Theory and the Maximum Utilization of the Available Distinctive Features Principle in a Perception-for-Action-Control Theory. Experimental Approaches to Phonology. Solé M., Speeter Beddor P. and Ohala M. (Eds.). Oxford: Oxford University Press. USA: New York. p.104-124.

Webster's Encyclopedic Unabridged Dictionary of the English Language (1996). Random House. USA: New York. 